\title{
Master regulators of wood formation in Eucalyptus
}

\author{
Hua Wang ${ }^{1}$, Marcal Soler ${ }^{1}$, Hong Yu ${ }^{1}$, Eduardo Leal Oliveira Camargo ${ }^{2}$, Hélène San Clemente ${ }^{1}$, Bruno Savelli' \\ Nathalie Ladouce 1 , Jorge Paiva ${ }^{3}$, Jacqueline Grima-Pettenati ${ }^{*}$ \\ From IUFRO Tree Biotechnology Conference 2011: From Genomes to Integration and Delivery \\ Arraial d'Ajuda, Bahia, Brazil. 26 June - 2 July 2011
}

With the current global focus on bioenergy, forest plantations are increasingly becoming important sources for second generation biofuel, where the whole plant lignocellulosic biomass is to be mobilized. The lignocellulosic biomass is mainly composed of secondary walls (SW) possessing unique characteristics (biochemical composition and tridimensional association of polymers), which govern the intrinsic properties of wood. They especially contain high amounts of lignins, hydrophobic phenolic polymers which constitute an obstacle to the optimal utilization of plant species in paper industry and for saccharification prior to bioethanol production. Among perennial species, Eucalyptus species grow very fast and produce high yields of lignocellulosic biomass. They represent the main industrial plantations in the worldand one of the most appealing lignocellulosic feedstock for bioenergy production. Dissection of the molecular switches controlling the coordinated lignin biosynthetic genes is therefore of utmost importance to understand the molecular mechanisms underlying tissue specific deposition of lignin and be able to improve secondary cell wall properties.

With the objective of improving Eucalyptus wood quality to better-fit industrial applications, we are focusing our efforts towards the identification and functional characterisation of regulatory genes controlling the biosynthesis of the cell wall polymers (mainly lignins).

We performed a precise mapping and functional characterization of the cis-regulatory elements contained in the promoters of two genes encoding key and consecutive steps of the lignin biosynthetic pathway i.e. Cinnamoyl CoA reductase (CCR) and Cinnamyl Alcohol

\footnotetext{
* Correspondence: grima@lrsv.ups-tlse.fr

'LRSV, UMR 5546 Université Toulouse III /CNRS, BP 42617, 31326 CastanetTolosan, France

Full list of author information is available at the end of the article
}

dehydrogenase (CAD) (Rahantamala et al, 2010). Our results supported a major role for the MYB transcription factors (TF) consensus sites in the control of the coordinated expression of these two genes. The functional analysis of two MYB factors (EgMYB1 and EgMYB2) preferentially expressed in Eucalyptus xylem revealed that they are able to bind specifically to these promoters and regulate transcriptionin vivo. EgMYB1 behaves as a repressor whereas EgMYB2 is an activator (Goicoechea et al, 2005, Legay et al, 2010) of the lignin biosynthetic genes but also of the secondary wall biosynthesis. Indeed, both MYBs were shown recently to be master genes regulating the entire secondary wall biosynthetic program including cellulose, xylan and lignin genes (Zhong et al, 2010; Legay et al 2010). The presence of both positive and negative regulators in Eucalyptus xylem offers the possibility of a combinatorial control of gene expression that could provide the necessary flexibility to ensure tight temporal and spatial regulation of lignin biosynthesis or secondary cell wall.

To address this question and get a deeper insight the complex regulation of the SW formation in Eucalyptus, we are now studying the regulation of these two MYBs including fine spatial and temporal expression, identification of their direct targets genes and of their protein partners. We have constructed a yeast-two-hybrid library from Eucalyptus xylem that will also be instrumental for deciphering the interactants of landmark genes for the International Eucalyptus community. Thanks to the recent release of the E. grandis genome (Eucalyptus grandis Genome Project 2010, http://www.phytozome. net/eucalyptus), we have performed a genome-wide survey of the large R2R3-MYB superfamily. The phylogenetic comparison of this family with Arabidopsis, rice, poplar and grapevine showed a marked expansion of some clusters putatively involved in wood-related 
processes. Some R2R3 MYB genes seem to be specific of woody plants. The spatiotemporal expression patterns of members of such clusters are currently being studied. Although Auxin is known as a key regulator of cambium activity and wood formation, the Auxin response mediators [Auxin/Indole-3-Acetic Acid (Aux/IAA) and Auxin Response Factor (ARF) transcription factors] extensively characterized in model plants, are still largely uncharacterized in tree species. We have identified $23 A u x / I A A$ and $17 A R F$ in the E. grandis genome. Comparative phylogenetic analysis revealed that several $A u x / I A A$ and $A R F$ subgroups have differentially expanded or contracted amongst the three dicotyledonous plants studied (Arabidopsis, Populus and Eucalyptus). Expression analysis and EST database surveys are currently underway to explore the transcript levels of each member in the different organs and tissues of Eucalyptus at key developmental stages as well as in response to hormonal treatments and to environmental stresses. Further functional genomics studies conducted on new candidate transcription factors, their regulation under the developmental or environmental stimuli will help identifying major factors underpinning the physicochemical properties of cell walls, the recalcitrance of which remains a key scientific challenge for establishing highly efficient, sustainably produced, second-generation biofuels.

\section{Author details}

'LRSV, UMR 5546 Université Toulouse III /CNRS, BP 42617, 31326 CastanetTolosan, France. ' 2 LRV, UMR 5546 Université Toulouse III /CNRS, BP 42617, 31326 Castanet-Tolosan, France//LGE, IB, UNICAMP, Campinas, Sao Paulo, Brazil. ${ }^{3}$ IICT/MCTES - Palácio Burnay - Rua da Junqueira, 30, 1349-007 Lisboa, Portugal.

Published: 13 September 2011

doi:10.1186/1753-6561-5-S7-P110

Cite this article as: Wang et al:: Master regulators of wood formation in Eucalyptus. BMC Proceedings 2011 5(Suppl 7):P110.
Submit your next manuscript to BioMed Central and take full advantage of:

- Convenient online submission

- Thorough peer review

- No space constraints or color figure charges

- Immediate publication on acceptance

- Inclusion in PubMed, CAS, Scopus and Google Scholar

- Research which is freely available for redistribution

Submit your manuscript at www.biomedcentral.com/submit
C Biomed Central 